\title{
Effect of Material Property in Foundation during Earthquake on the Embankment
}

\author{
Behrouz Gordan ${ }^{1}$ and Azlan Bin Adnan ${ }^{2}$ \\ ${ }^{1}$ Faculty of Civil Engineering, Universiti Teknologi Malaysia, 81310 Skudai Johor, Malaysia \\ ${ }^{2}$ Earthquake Department, Universiti Teknologi Malaysia, 81310 Skudai Johor, Malaysia
}

Correspondence should be addressed to Azlan Bin Adnan, azelan_fka_utm@yahoo.com

Received 15 August 2012; Accepted 2 October 2012

Academic Editors: I. Raftoyiannis and D. Zeng

Copyright ( 2012 B. Gordan and A. B. Adnan. This is an open access article distributed under the Creative Commons Attribution License, which permits unrestricted use, distribution, and reproduction in any medium, provided the original work is properly cited.

\begin{abstract}
The dynamic analysis process started after any loss of embankment with associated huge damages like cracks during the earthquake. Literature review indicated that the maximum displacement during the earthquake is conducted to the crest and interface between the embankment with water reservoir, and foundations were cased. This paper evaluated the effect of material properties of the foundation for the two conditions so the result is related at the end of construction with supplying water. Numerical analyses of models were performed by finite element with plane strain method and ANSYS13 software. Earthquake recording as Nagan with 5.02 seconds and peak ground acceleration equal to PGA $=0.65$ is used. Results indicated that with a comparison of horizontal and vertical displacement, shear strain and shear stress so nonisotropic behavior of embankment especially in the up to part of the structure was obvious. It is required to consider an improvement of dynamic settlement with reinforcement structure in the future.
\end{abstract}

\section{Introduction}

Design control of dynamic settlement in embankment is essential because there are good samples that were ruined during an earthquake. Therefore, it seems to be a specific attention to investigate and best research the influence of the dynamic load settlement of embankment during the earthquake. From the literature, review indicated that since the beginning of 1920s and up to 1960s "pseudo-static method" of analysis was well known. However, this method was very simple, and it does not take into account the nature of the slope-forming material or the foundation material. In the year 1965, based on deformation characteristics, Newmark [2] proposed "sliding block method". Among other methods, "shear beam model" analysis was quite popular. This method was introduced by Mononobe [3] Gazetas [4] proposed an improved "inhomogeneous shear beam model" which can take care of the fact that the shear modulus in earth or rock-fill dams is not constant but increases with $2 / 3$ power of depth from the crest. Clough and Chopra [5] introduced the finite-element method for twodimensional plane-strain analysis to estimate of the dynamic response of an embankment assuming that it consists of linearly elastic, homogeneous, isotropic materials. Later on, several other researchers developed the finite-element and finite difference method for nonlinear, inelastic, nonhomogeneous, anisotropic behavior of materials under seismic conditions. Zeghal and Abdel-Ghafar [6] proposed a localglobal finite element method of analysis for determination of the nonlinear seismic behavior of earth dams. Ming and Li [7] conducted a fully coupled finite-element analysis of failure of the Lower San Fernando dam and examined the possible reason of the dam failure. Quick development of computer programs had a useful information of earthquake engineering research. For example, several computer programs like [8-11] are used worldwide for the intensive seismic analysis of the earthen dam. Seid-Karbasi and Byrne $[12]$ and Piao et al. $[13,14]$ carried out dynamic analysis of the earthen dams using the finite difference method based computer code FLAC. Zhu et al. [15] have presented a twodimensional seismic stability for a levee embankment using finite element based program PLAXIS [16]. Literature review indicated that the maximum displacement during dynamic loading is conducted to the crest and interaction between 


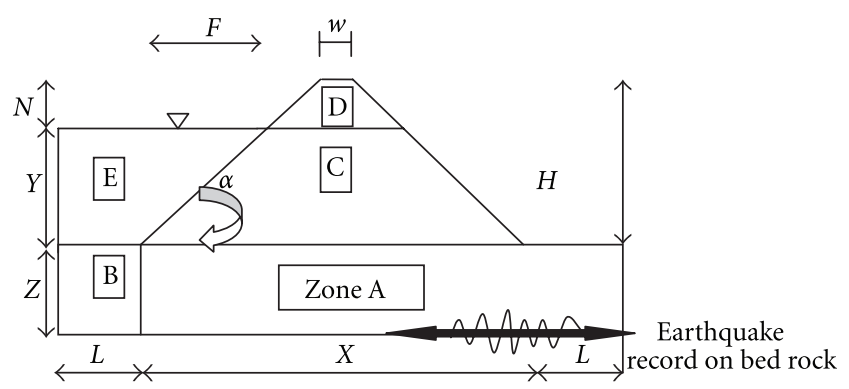

FIgURE 1: A dimension of models according to Table 1 for plan strain analyses.

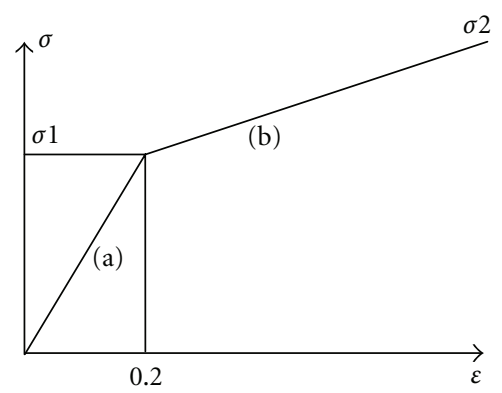

FIGURE 2: This figure illustrated nonlinear property of soil.

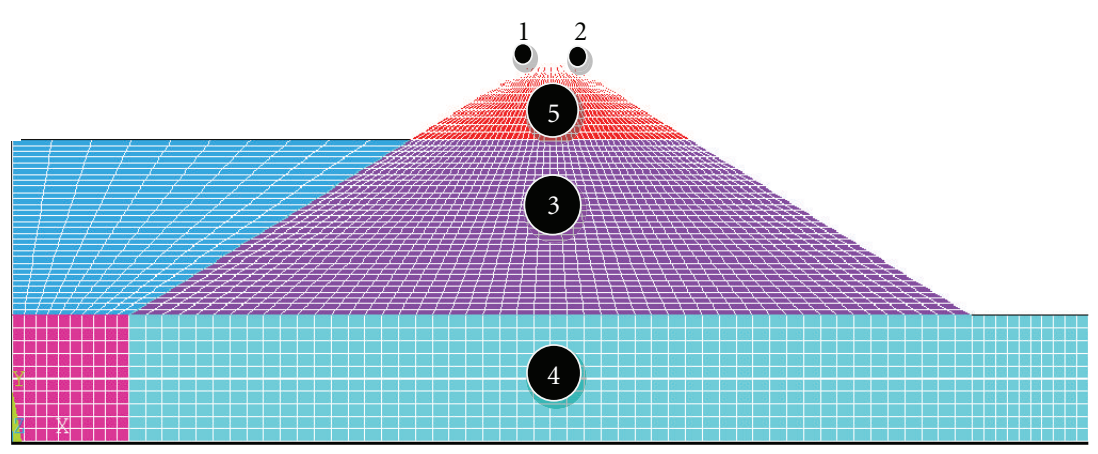

FIgURE 3: This figure illustrated that mesh of the model with regular method and main points (1-5) to exist a data analysis.

TABle 1: A dimension of models.

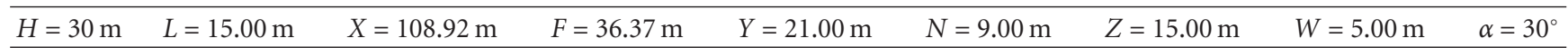

TABLE 2: Material properties.

\begin{tabular}{|c|c|c|c|c|c|c|}
\hline Zone & $\begin{array}{c}\text { Relative } \\
\text { density } \\
\left(\mathrm{Kg} / \mathrm{m}^{3}\right)\end{array}$ & $\begin{array}{c}\text { Elasticity } \\
\text { modulus } \\
\left(\mathrm{Kg} / \mathrm{m}^{2}\right)\end{array}$ & $\begin{array}{c}\text { Poisson } \\
\text { ratio }\end{array}$ & $\begin{array}{c}\text { Yield stress } \\
\left(\mathrm{Kg} / \mathrm{m}^{2}\right)\end{array}$ & $\begin{array}{l}\text { Tangent } \\
\text { modulus }\end{array}$ & $\begin{array}{c}\text { Friction } \\
\text { coefficient }\end{array}$ \\
\hline A1—foundation (loose-sand saturated) & 800 & $3 * 10^{6}$ & 0.25 & $1.20 * 10^{4}$ & 0.01 & 0.30 \\
\hline A2-foundation (clay-saturated) & 800 & $8 * 10^{5}$ & 0.45 & $3.20 * 10^{3}$ & 0.01 & 0.10 \\
\hline B1-foundation (loose-sand saturated) & 800 & $3 * 10^{6}$ & 0.25 & $1.20 * 10^{4}$ & 0.01 & 0.30 \\
\hline B2-foundation (clay-saturated) & 800 & $8 * 10^{5}$ & 0.45 & $3.20 * 10^{3}$ & 0.01 & 0.10 \\
\hline C-embankment (saturated) & 900 & $2 * 10^{6}$ & 0.45 & $8.00 * 10^{3}$ & 0.01 & 0.001 \\
\hline D_embankment (unsaturated) & 1900 & $4 * 10^{5}$ & 0.30 & $1.60 * 10^{3}$ & 0.01 & - \\
\hline $\mathrm{E}$-water & 1000 & $1 * 10^{12}$ & 0.001 & - & - & - \\
\hline
\end{tabular}




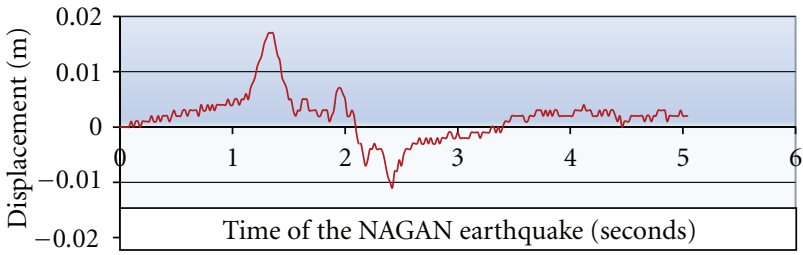

FIgUre 4: This is related to inputting data of NAGAN earthquake record so displacement in the vertical axis $(\mathrm{m})$ and time on the horizontal axis (second).

a dam, and foundation is caused to it. This paper considered the effect of material property as the foundation for a dynamic settlement for isotropic embankment saturated according to the end of construction with supplying water.

\section{Process of the Model}

This procedure introduced a numerical dynamic analysis of modeling step by step.

2.1. Introduce ANSYS Software. This software is comprehensive by finite-element method and has 100000 codeine. However, this is related to Computer Aided Engineering (CAE), and is very famous and popular. In fact, it is universal in most of the finite-element software.

2.2. Element. In this research solid 42 elements for all parts of the structure (shell, core, foundation) and fluid 79 elements for water reservoir to model with plane strain $2 \mathrm{D}$ method according to recommendations by ANSYS help were used.

2.3. Boundary Conditions. For a dynamic analysis of the model, Nagan earthquake is used with acceleration-time, and it was converted to displacement-time by SISMOSOFT3 software. After that, the total horizontal displacement shown 0.43 meters at the end of earthquake records. Most of the famous records in the literature had a half value of the horizontal PGA for the vertical direction. Therefore, the value of the vertical displacement total equal to 0.2 meters was performed. Furthermore, vertical displacement in the horizontal boundary (bedrock) was zero and input data of NAGAN record is used for horizontal displacement of boundary. In addition, both lines of vertical's boundary had a vertical total displacement equal to 0.2 meters and 0.01 meters for horizontal displacement so that it was related to transient property of waves in the model for transfer and come back.

2.4. Parametric Model. Table 1 described the parametric dimensional model for both embankment models with different material properties in the foundation.

A parametric dimensions of the models illustrated in Figure 1, and the earthquake is performed on the base of the model and material properties like to zones (A, B, C, D, and E) described in Table 2.
2.5. Material Properties. In this part we introduce three section properties for water, foundation, and embankment. The body of the structure was clay with isotropic property so material of foundation soft soil saturated (loose sand), and clay saturated in the first and second model were used, respectively. Furthermore, ANSYS Liquid suggested that water was non compressible according to Table 2. Moreover, Table 2 introduced material property in each zone of the model for two conditions of the foundation and behavior of solid material was according to hardening isotropic bilinear so the friction coefficient is related to contacting model for the best interaction effect. It noted that model 1 is performed with (A1, B1, C, D, and E) and model 2 with (A2, B2, C, D, and $\mathrm{E}$ ) too. In addition to choose value for soil properties [17] is referenced.

This study included the nonlinear behavior of soil and some items such as density, Yang modulus, and Poisson's ratio stress with tangent modulus for bilinear isotropic hardening for solid material were used so huge elasticity modulus for non-compaction behavior of water according to a suggestion by the help menu of ANSYS to linear behavior of the water reservoir is used. Moreover, Figure 2 is related to the nonlinear behavior of soil to evaluate analysis and described the behavior of solid materials in Table 2. This figure had performance two parts such as line (a) for elastic and line (b) to evaluate of elasto-plastic and plastic conditions.

Line (a) was introduced according to Yang's modulus and $\sigma 1$ with the poisson's ratio, and line (b) was the simulation of nonlinear behavior with gradient slope that means tangent modulus for modeling with bilinear isotropic hardening of solid material in the ANSYS software.

It noted that value of $\sigma 2$ was equal to two times of value of $\sigma 1$ and it was obvious that $\sigma 1$ was related to the yield stress according to fixed strain that it was 0.2 (laboratory test).

Furthermore, $\sigma 2$ was performance failure stress according to the gradient slope of the line (b) so horizontal and vertical axis represented strain and stress, respectively, so this figure introduced a simplification of the nonlinear property curve.

2.6. Meshing and Main Points. Figure 3 illustrated that plan mesh is performed so regular mesh for effect of interaction with node to node of models is used. Moreover, five main points (1-5) to evaluate existing data were chosen that both were at the crest (1-2) and another was the middle of zones in $\mathrm{C}-\mathrm{A}$ and $\mathrm{D}(3-4-5)$.

2.7. Earthquake Record. Both models were evaluated by NAGAN record. This record had an acceleration-time with $\mathrm{PGA}=0.65$ and 5.02 seconds of time. Moreover, the record is converted to displacement-time for input data in ANSYS by SISMOSOFT3 software. Figure 4 shows displacement-time record of NAGAN.

This figure indicated that maximum and minimum displacement were $16.5 \mathrm{~mm}$ and $11 \mathrm{~mm}$, respectively. All the substeps were 0.02 seconds and records were 5.02 second only with PGA $=0.65$ so PGA was peaked at ground acceleration. 


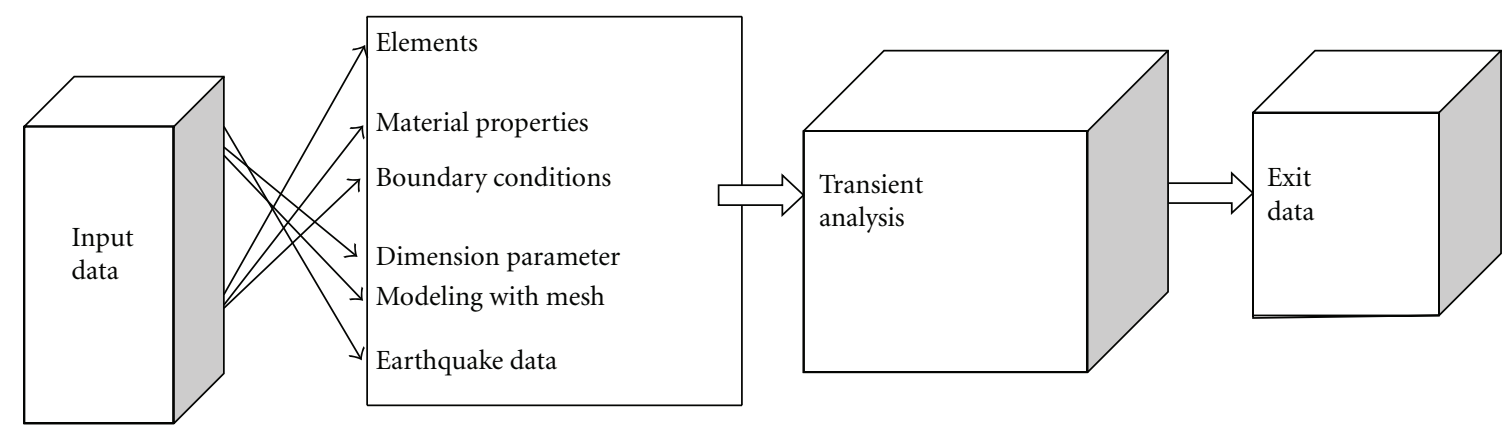

FIGURE 5: Process of the numerical analysis.

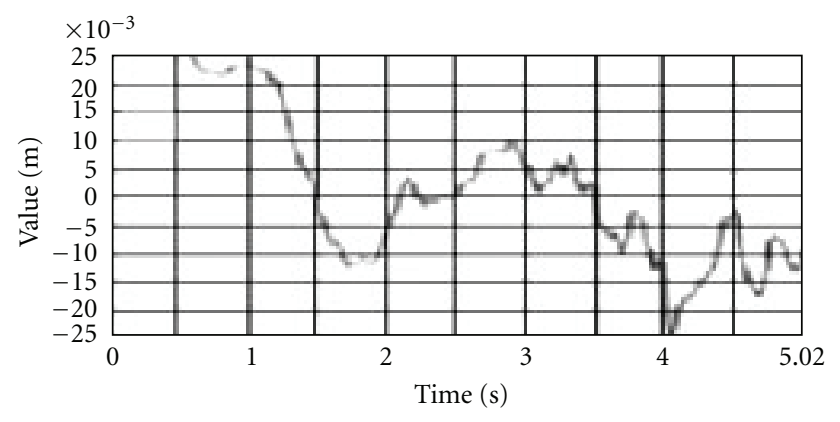

Figure 6: Vertical displacement-time in the point number 4 to analysis settlement during the earthquake so horizontal axis is a time (second) and the vertical axis is displacement (meter).

2.8. Chart of Modeling. This chart introduced a process of numerical modeling, and Figure 5 represented that it included three steps such as input data, transient analysis, and exit data.

\section{Result Analysis}

Numerical analyses on both the models were calculated by Nagan record with displacement-time. Furthermore, Figures 6 and 7 illustrated nonlinear behavior of material during dynamic load.

In addition, Figure 7 illustrated that value of shear stress during dynamic loading. This figure presented value of the $X Y$ Shear stress in each substep of dynamic load and indicated that some of the substeps were positive or negative valued, and it was related to the nonlinear behavior of analysis during an earthquake. All the nodes had a same and regular process. Furthermore, this function was very great to an analysis by ANSYS.

Comparison of the horizontal displacement of both of models is illustrated by Figure 8 . It was found that the value of displacement in model 1 (lose sand foundation) is less than model 2 (clay foundation) so it was related to reducing of value in the modulus elasticity and increase of coefficient friction value. In fact, model 2 had more sliding rather than model 1 and less value of coefficient friction in model 2 and more sliding led to increase of horizontal displacement. In addition maximum horizontal displacement was related to point 4 that it was in the middle of saturated embankment and near to the best effective at water pressure according to the static pressure in the $1 / 3$ of the height of the embankment that was clearly in the literature review. All the results for model 1 and model 2 were corresponded to series 1 and series 2 , respectively.

Figure 9 illustrated vertical displacement or dynamic settlement for both of the models. It was revealed that the value of the settlement in model 1 (lose sand foundation) in the crest is less than model 2 (clay foundation) so it was related to reduced modulus elasticity value in model 2. Modulus in model 1 was more than model 2 , and it led to reducing the value of the vertical displacement in model 1 rather than model 2 because reduction of modulus led to increase of flexibility and settlement. Furthermore, maximum settlement is conducted to point 5 , and it was in the middle of the crest in both the models so indicated that according to low thickness of foundation in models caused to minimum resistance of released energy of earthquake and less damping in this zone in both models. In addition in both the models value for the settlement in the both points in the crest (1 and 2) were not equal, and it was another validat of results according to literature about differential settlement but this value in model 2 was more than model 1. Furthermore, Figure 10 is related to cracks in the crest of an embankment in India so differential settlement in the crest was caused [1].

The values of shear strain in both of the models were illustrated in Figure 11 and maximum values were related in the middle of nonsaturated part of the embankment (D, according to Figure 1), and it was related to reduction of Poisson's ratio in this part rather than saturated embankment, and this figure represented that the value of the shear strain in both of the models were closed. However, point 3 value of shear strain in model 1 was more than model 2 and the value of Poisson's ratio in the foundation in model 1 was 0.30 so it was 0.45 for model 2 and equal to nonsaturation embankment so variety of Poisson's ratio in the foundation led to different values of shear strain.

The values of shear stress in both of the models were illustrated in Figure 12 and maximum values were related in the middle of nonsaturated part of the embankment 


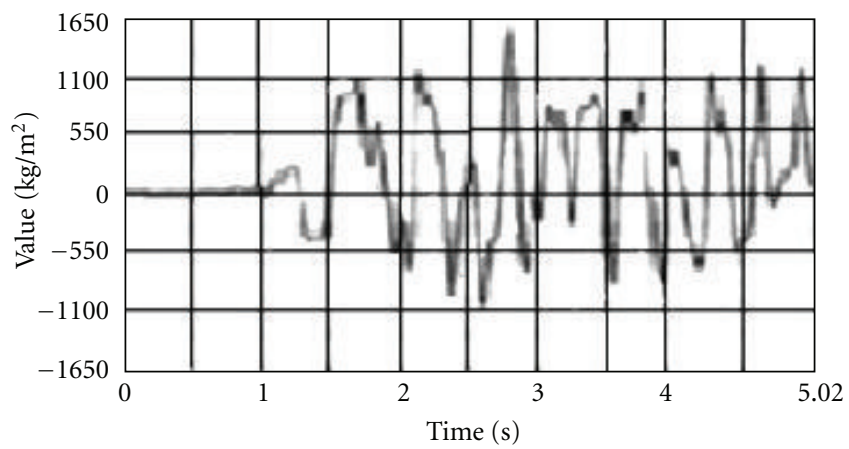

FIGURE 7: $X Y$ shear stress in the point number 5, in the substep of earthquake so horizontal axis is time (second) and the vertical axis is $X Y$ shear stress $\left(\mathrm{kg} / \mathrm{m}^{2}\right)$.

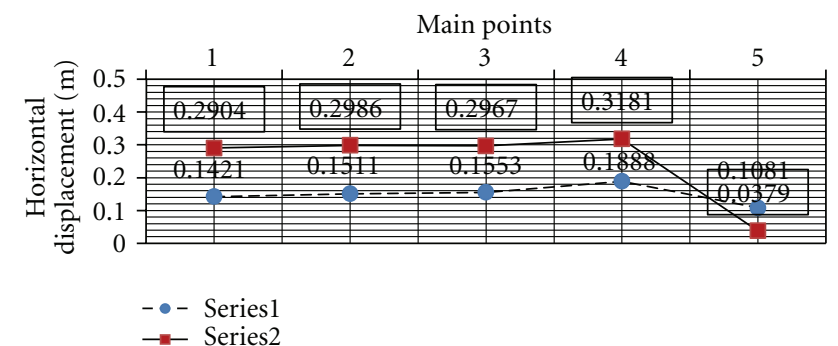

Figure 8: Horizontal dynamic displacement $(\mathrm{m})$ in the end of earthquake for both models. The horizontal axis is main points, and the vertical axis is horizontal dynamic displacement (meter).

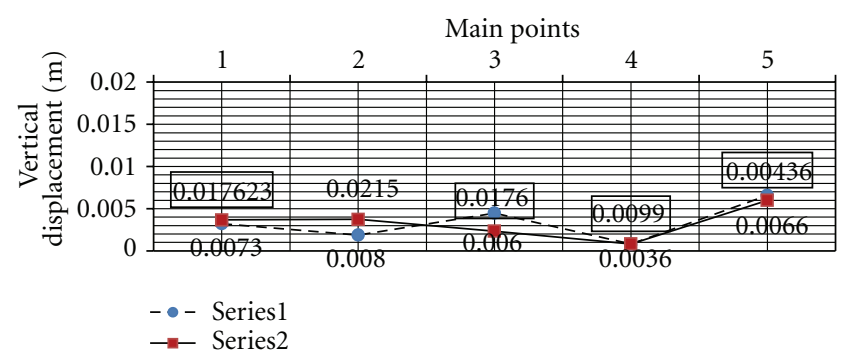

FIGURE 9: Vertical dynamic displacement at the end earthquake for both of models. The horizontal axis is main points, and the vertical axis is dynamic settlement displacement (meter).

(D, according to Figure 1), and it was related to reduction of Poisson's ratio and modulus elasticity in this part rather than saturated embankment.

\section{Conclusion}

Effects of foundation properties in the embankment on the dynamic analysis were evaluated during this study. Maximum horizontal displacement depends on the value of coefficient friction and increase of it ceased to the reduction of sliding and horizontal displacement. Furthermore, dynamic settlements depended upon the value of the modulus elasticity and reduction of this value led to increase of flexibility and dynamic settlement. Moreover, variations

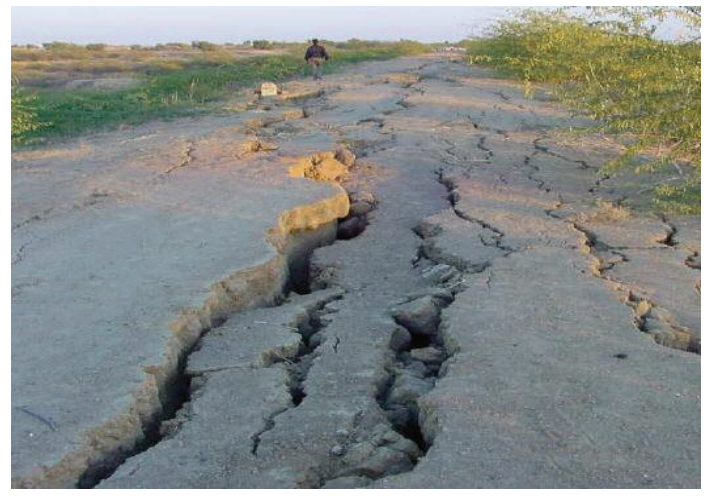

FIGURE 10: Cracking and inelastic deformations of the crest of the embankment dam caused by the 2001 Bhuj earthquake in India. The prediction of cracks and damage requires nonlinear dynamic analyses. It was sorted by [1].

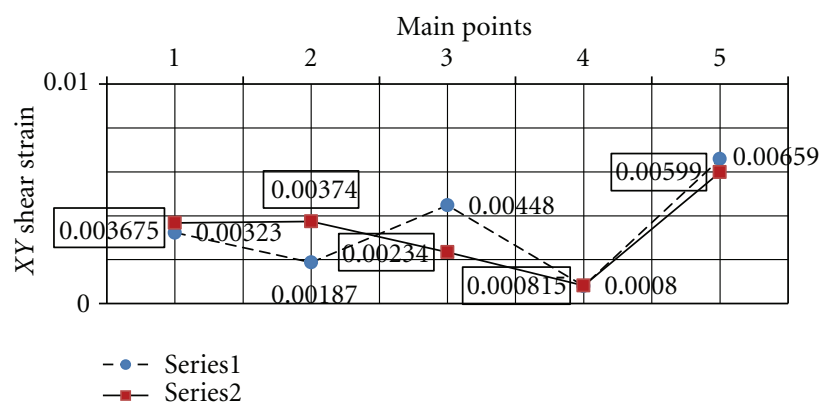

FIGURE 11: $X Y$ shear strain at the end of earthquake for both models. The horizontal axis is main points, and the vertical axis is an $X Y$ shear strain.

of shear strain were closed in both models but value as the shear stress indicated that the non isotropic behavior of the embankment in the nonsaturated part on the model has been caused to increase of shear stress on this area. In addition, numerical analysis had a good agreement with literature review and attention to the improvement of the isotropic function of embankment, especially in the nonsaturated part of structured, is important for the future. 


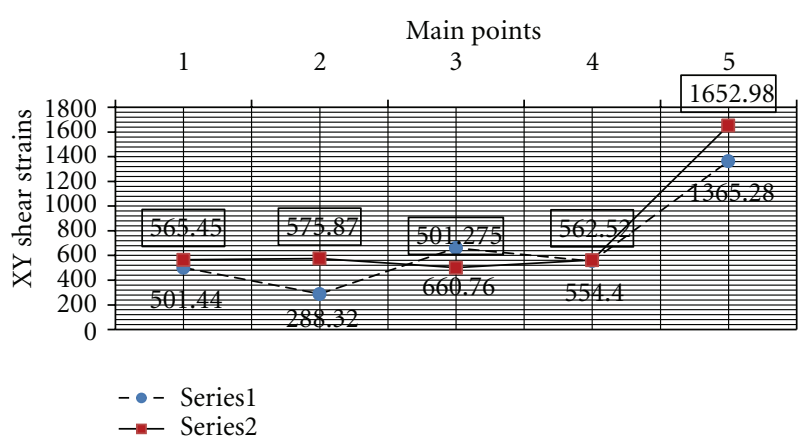

FIGURE 12: $X Y$ shear stress in the end of earthquake for both of the models. The horizontal axis is main points, and the vertical axis is $X Y$ shear stress $\left(\mathrm{kg} / \mathrm{m}^{2}\right)$.

\section{Acknowledgment}

This study was made possible by the support of the International Doctorate Fellowship of Universiti Teknologi Malaysia, and it is very much appreciated.

\section{References}

[1] M. Wieland, "Analysis aspects of dams subjected to strong ground shaking," 2008, http://www.waterpowermagazine.com/.

[2] N. M. Newmark, "Effects of earthquakes on dams and embankments," Geotechnique, 15: 139-160, 1965, http://www .civil.ubc.ca/liquefaction/Publications/Hydropower \&Dams .pdf.

[3] H. A. Mononobe, "Seismic stability of the earth dam," in Proceeding of the 2nd Congress on Large Dams (CLD '36), pp. 435-442, Washington, DC, USA, 1936.

[4] G. Gazetas, "New dynamic model for earth dams evaluated through case histories," Soils and Foundations, vol. 21, no. 1, pp. 67-78, 1981.

[5] R. W. Clough and A. K. Chopra, "Earthquake stress analysis in earth dams," Journal of Engineering Mechanics, vol. 92, pp. 197-211, 1966.

[6] M. Zeghal and A. M. Abdel-Ghafar, "Local global finite element analysis of the response of earth dams," Computers \& Structures, vol. 42, pp. 569-579, 1992.

[7] H. Y. Ming and X. S. Li, "Fully coupled analysis of failure and remediation of Lower San Fernando Dam," Journal of Geotechnical and Geoenvironmental Engineering, vol. 129, no. 4, pp. 336-349, 2003.

[8] M. Hudson, I. M. Idriss, and M. Beikae, "User's manual for QUAD4M. Center for Geotechnical Modeling, Department of Civil and Environmental Engineering, University of California, Davis, Calif, USA,” 1994, http://cgm.engineering. ucdavis .edu/Publications/reports/Quad4Mmanualrev2003.pdf.

[9] ITASCA, "Fast Lagrangian analysis of continua. Version 4, User's Guide, ITASCA Consulting Group, Minneapolis, Minnesota, USA," 2000, http://www.aimil.com/flac3d.aspx.

[10] G. A. Ordóñez, "SHAKE2000: A computer program for the 1D analysis of geotechnical earthquake engineeringproblems," 2000, http://www.shake2000.com/index.html.

[11] TAGA soft Limited, "TELDYN-Users'manual. Lafayette, California," 1998, http://www.tagasoft.com/.
[12] M. Seid-Karbasi and P. M. Byrne, "Embankment dams and earthquakes," International Journal on Hydropower and Dams, vol. 11, no. 2, pp. 96-102, 2004.

[13] R. Piao, A. H. Rippe, B. Myers, and K. W. Lane, "Earth dam liquefaction and deformation analysis using numerical modeling," in Proceeding of the Geo Congress (GC'06), pp. 1-6, American Society of Civil Engineers, 2006.

[14] R. Piao, A. H. Rippe, B. Myers, and K. W. Lane, "Earth dam liquefaction and deformation analysis using numericalmodeling," American Journal of Engineering and Applied Sciences, vol. 2, no. 3, pp. 559-564, 2009.

[15] Y. Zhu, K. Lee, and G. H. Collison, "A 2D seismic stability and deformation analysis. Proceeding of the GeoFrontiers, Jan. 24-26, ASCE., Austin, Texas, pp: 1-15,” 2005, http://www.golder.com/archive/2005Geo_PTFI.pdf.

[16] R. B. J. Brinkgreve, R. Al-Khoury, K. J. Bakker, P. G. Bonnier, P. J. W. Brand et al., PLAXIS 2D-Version 8 Full Manual, Amsterdam, The Netherlands, 2002.

[17] P. Mestat, "Lois des comportement des geomateriaux et modelisation par la methode des elements finis," in Etudes et Recherches des Laboratories des Ponts et Chaussees, Serie Geotechnique:GT52, 1993. 

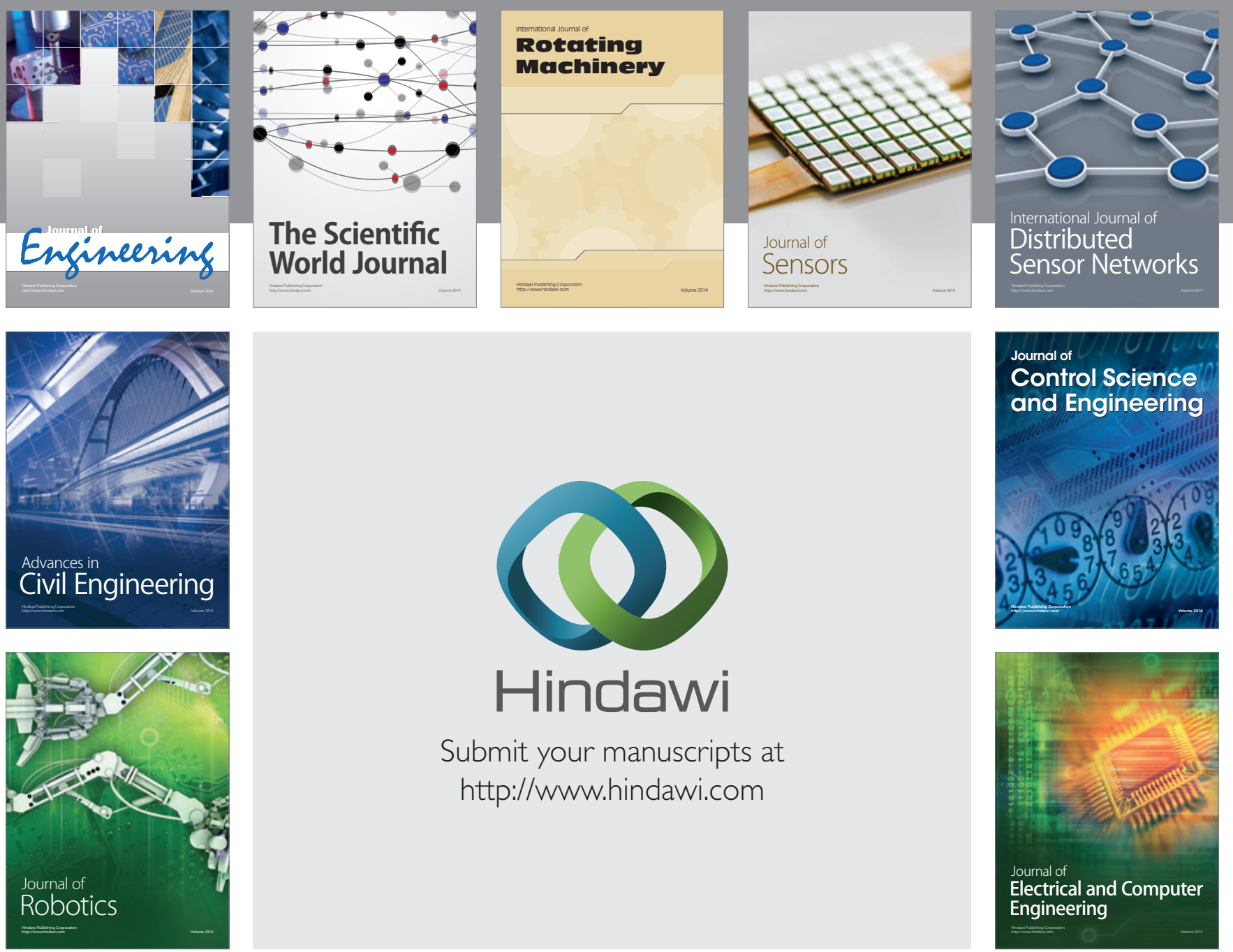

Submit your manuscripts at

http://www.hindawi.com
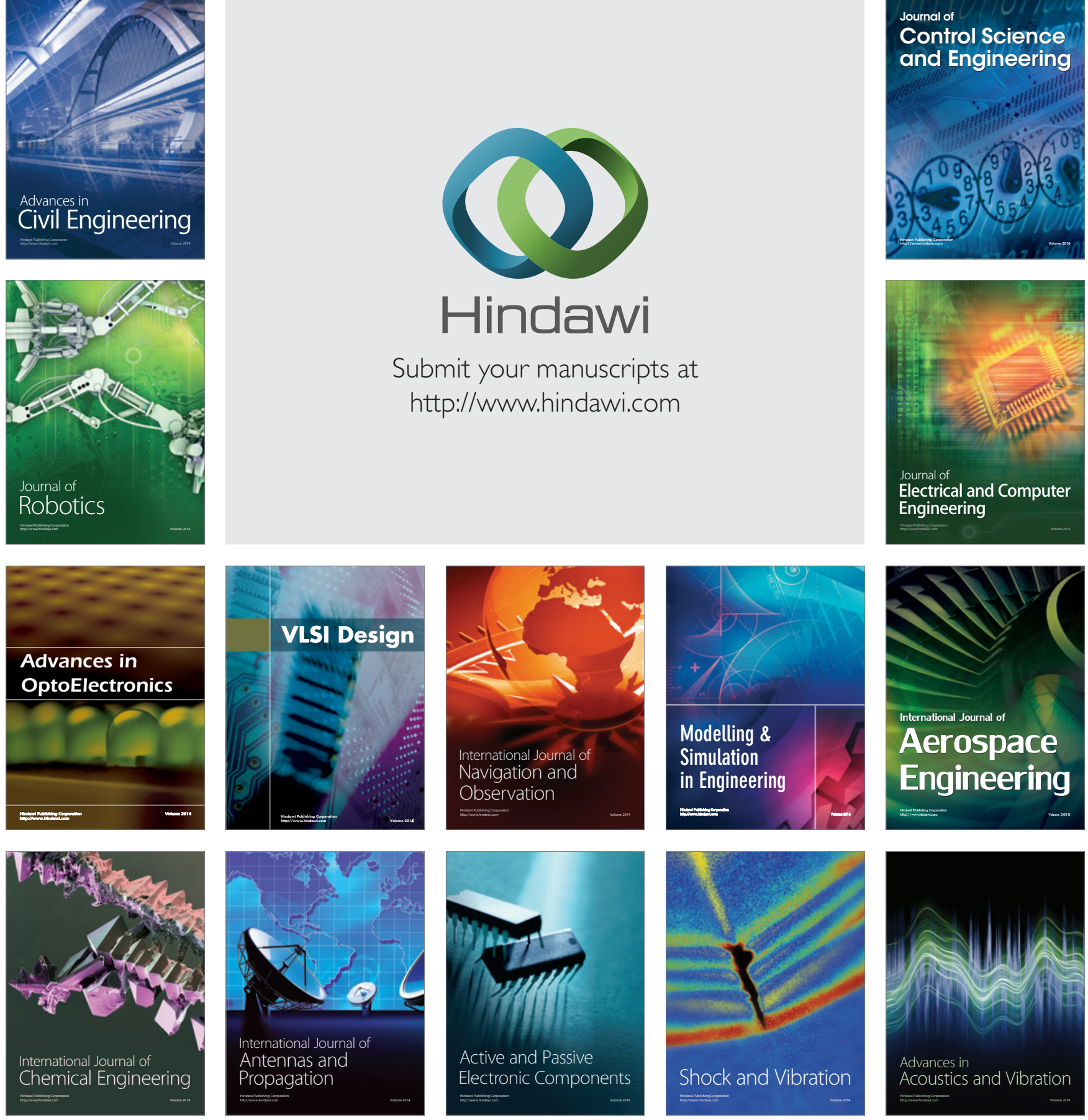